\title{
Resistance in cultivated barleys to Pyrenophora teres f. teres and prospects of its utilisation in marker identification and breeding
}

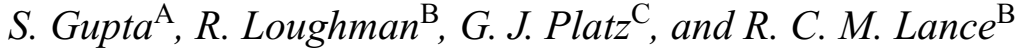 \\ ${ }^{A}$ WA State Agricultural Biotechnology Centre, Murdoch University, WA 6150, Australia. \\ ${ }^{B}$ Crop Improvement Institute, WA Department of Agriculture, South Perth, WA 6151, Australia. \\ ${ }^{\mathrm{C}}$ Agency of Food and Fibre Sciences, Queensland Department of Primary Industries, Hermitage Research Station, \\ Warwick, Qld 4370, Australia.
}

\begin{abstract}
Net type net blotch (NTNB) is a prevalent disease in Australia, causing significant losses in barley yield and quality. Its impact can be reduced with the identification and utilisation of effective sources of resistance. Sixtynine cultivated barley lines were screened as seedlings against 9 isolates of Pyrenophora teres f. teres from Australia, and in the field in Western Australia. Resistance expressed in seedlings was frequently expressed in adult plants in the field, indicating that these sources are potentially useful for resistance breeding. Of these lines, 24 with the best overall resistance were identified, which could be used against virulence diversity present in P. teres f. teres in Australia.

As a prelude to the evaluation of established mapping populations in the Australian Barley Molecular Marker Program, 42 parental lines were screened against a range of Australian isolates of $P$. teres $\mathrm{f}$. teres. Variation in net blotch responses was observed among parents of the mapping populations. Ten principal mapping populations appear to provide opportunities to map resistances and identify molecular markers linked to NTNB resistance genes effective against Australian pathotypes.
\end{abstract}

Additional keywords: net type net blotch resistance, mapping populations, variance, REML analysis.

\section{Introduction}

Pyrenophora teres f. teres Drechs. (anamorph: Drechslera teres f. teres (Sacc.) Shoemaker), which causes net type net blotch (NTNB) in barley (Hordeum vulgare L. emend Bowden), is a prominent disease of widespread occurrence causing significant yield losses around the world (Sutton and Steele 1983; Deadman and Cooke 1987; Steffenson et al. 1991; Mathre 1997). In field experiments, Khan (1987) estimated mean yield loss of $21 \%$ with a maximum loss of $37 \%$ in cv. Dampier, and Poulsen et al. (1999) reported over $50 \%$ losses in Queensland. In Western Australia, most of the cultivars have been susceptible and recent virulence studies indicated that 2 main virulences have remained unchanged in this region over a 20-year period (Gupta and Loughman 2001). Elsewhere in Australia, the variability of NTNB virulence is higher, and the breakdown of resistance in cvv. Gilbert and Grimmett in Queensland in 1993 demonstrated that new pathotypes of this fungus are evolving (Platz et al. 2000). At least 13 pathotypes are represented in the Australian population (Platz et al. 2000). Similarly high pathotype variability has been found in most barley growing regions of the world (Tekauz 1990; Steffenson and Webster 1992; Afanasenko et al. 1995; Jonsson et al. 1997).
The use of diverse and effective combinations of resistance genes is an economical and environmentally preferred method to minimise yield loss and improve quality of Australian barley. Khan (1971) studied Turkish germplasm and found 6 lines resistant to Western Australian NTNB pathotypes. These lines varied in response when tested under wider environmental conditions, compared with resistance in lines from Ethiopia and Manchuria. Khan (1982) also found barley lines CI5791 and CI7584 as resistant against NTNB pathotypes present in the early 1980 s in Western Australia. Resistance has been reported in wild and cultivated barley lines against European (Arabi et al. 1992; Jonsson et al. 1997), Canadian (Jana and Bailey 1995; Legge et al. 1996), Japanese (Sato and Takeda 1997), and American (Douiyssi et al. 1998) pathotypes. None of these studies included $P$. teres f. teres isolates from Australia.

The pathotype variability present in Australian populations of the pathogen requires the identification of broadly effective sources of NTNB resistance. Stability of varietal resistance may be improved with the deployment of multiple resistance genes, preferably pyramided in combinations, recognised through the use of genetic markers linked to different resistance genes. 
NTNB resistances have been mapped on different chromosomes using various barley populations. Graner et al. (1996) reported an NTNB resistance gene on chromosome 3 in cv. Igri, using restriction fragment length polymorphism markers. Steffenson et al. (1996) identified 7 chromosomal regions linked to NTNB resistance in Steptoe. Manninen et al. (2000) mapped a major resistance gene on chromosome 6 and epistatic locus on chromosome 5 in the barley population CI9819 $\times$ Rolfi. Similarly, Cakir et al. (2003, this issue) and Raman et al. (2003, this issue) mapped resistance on chromosomes 6, 3, 2, and 4 .

The Australian Barley Molecular Marker Program, established in 1997, provided opportunities to address the need for genetic mapping information on net blotch resistance. Research described in this paper was undertaken to identify broadly effective sources of resistance in Australia for NTNB-specific mapping. In addition, parental combinations of principal mapping populations were identified that could be used to target marker-trait associations with resistances against Australian isolates of P. teres f. teres.

\section{Materials and methods}

Barley lines

Sixty-nine barley lines as candidate resistance donors including several controls were used to test for broadly effective net blotch resistance (phase 1 lines). A further 42 parents and controls, represented in established populations of the Australian Barley Molecular Marker Program, were used to identify candidate populations for mapping net blotch resistance (phase 2 lines). All lines except Halcyon and Igri were spring types. Lines were drawn from public breeding programs around Australia, from elite nurseries where barley lines were tested for quality, agronomic performance, and other diseases, and from an extensive differential set used for pathotype screening in Australia (Platz et al. 2000; Gupta and Loughman 2001).

\section{Pyrenophora teres $f$. teres isolates}

The net blotch isolates used to screen phase 1 and 2 lines were from Australian barley growing areas where the disease has a significant effect on the crop. Nine isolates were used to screen the 69 candidate lines for resistance. A further set of 9 isolates (including one isolate in common) was used to differentiate net blotch response among the 42 parents used to develop mapping populations. The 17 isolates represented virulences known from Western Australia, Queensland, South Australia, and New South Wales (Platz et al. 2000).

\section{Single spore isolation and inoculum production}

Dried barley leaves with net blotch lesions were cut into 5-10 mm fragments and surface sterilised in $0.5 \%$ sodium hypochlorite solution for $2 \mathrm{~min}$, then double rinsed in sterile deionised water for $1 \mathrm{~min}$. Fragments were blotted dry and aseptically transferred to $2 \%$ water agar plates. Isolation plates were incubated at $15-18^{\circ} \mathrm{C}$ with $12 \mathrm{~h}$ near UV light/12 h dark. After 3-5 days, single conidia representing each collection were transferred to V8 agar medium plates. The resultant colonies were then subcultured to peanut oatmeal agar (POA) medium plates (Speakman and Pommer 1986) and held at $19^{\circ} \mathrm{C}, 12 \mathrm{~h}$ light for 9-10 days, when conidia were harvested for inoculation of the test plants.

\section{Inoculum and inoculation of host plants}

Barley lines were sown in 10-cm-diam. plastic pots in clumps of 10 seeds per line and 2 lines per pot using a pasteurised potting mix (2 parts river sand and 1 part peat moss with nutrients and trace elements). The plants were grown in the glasshouse at $18-22^{\circ} \mathrm{C}$ for 2 weeks or until the second leaf was fully unfurled.

Conidia were harvested from POA plates by adding sterile distilled water and scraping the surface of the culture with a rubber spatula. The spore suspension was filtered through gauze and adjusted to $2 \times 10^{4}$ conidia/mL, then applied at $2 \mathrm{~mL}$ per pot using a Paasche airbrush. The plants were placed in a mist chamber and leaf wetness maintained at $16-19^{\circ} \mathrm{C}$ for $24 \mathrm{~h}$ with an initial $14 \mathrm{~h}$ in dark. The plants were subsequently returned to the glasshouse to allow for symptom development. The tests were conducted in duplicate to determine reproducibility of infection types.

\section{Scoring infection types}

Infection types on the 2nd leaf were scored on the 9th day using the scale of Tekauz (1985). Infection types 1-3 were classified as resistant, 4 as moderately resistant, 5 as intermediate, and 6 and over as susceptible.

\section{Field assessment of candidate resistant lines}

Phase 1 lines were sown in a randomised block design with 2 replicates at experimental sites in South Perth in 1997 and at Shenton Park in 1998. Plots comprised a single $1-\mathrm{m}$ row of $10-15$ plants. Barley straw naturally infected with net blotch was applied at $50 \mathrm{~g} / \mathrm{m}^{2}$ at growth stage 14-15 (Zadoks et al. 1974). Plants in each plot were assessed for infection type according to Tekauz (1985), from leaves on which infection had advanced by anthesis. The mean percent diseased leaf area of 5 penultimate leaves per plot was assessed according to the scale of Hampton and Arnst (1978).

\section{Statistical analyses}

The duplicate seedling net blotch responses of the 69 phase 1 barley lines to 9 isolates of $P$. teres f. teres were subjected to variance components analysis using the restricted maximum likelihood (REML) procedure in Genstat (GENSTAT for Windows 6th Edition). Responses of lines were estimated as best linear unbiased predictors (BLUPS). These estimates take into account experimental error and are better predictors of performance than raw means. A combined REML analysis was run on 42 phase- 2 lines tested in duplicate in 2 experiments to 9 isolates. The field responses of phase 1 lines were analysed as a randomised complete block analysis of variance using GENSTAT.

\section{Results}

Two sets of barley lines were used for this work. In phase 1, sources of broadly effective resistances were identified against 9 . teres f. teres isolates. In phase 2 , the responses of 42 lines were screened with another set of 9 isolates to identify the candidate lines for the development of mapping populations of national interest under the Australian Barley Molecular Marker Program.

\section{Seedling responses of phase 1 candidate resistant parents}

The REML model assumed fixed effects due to set; random effects due to line and isolate within line. A variance/ covariance model allowed for different variances between isolates within each line and no correlation between lines. With this model we estimated that the variance component 


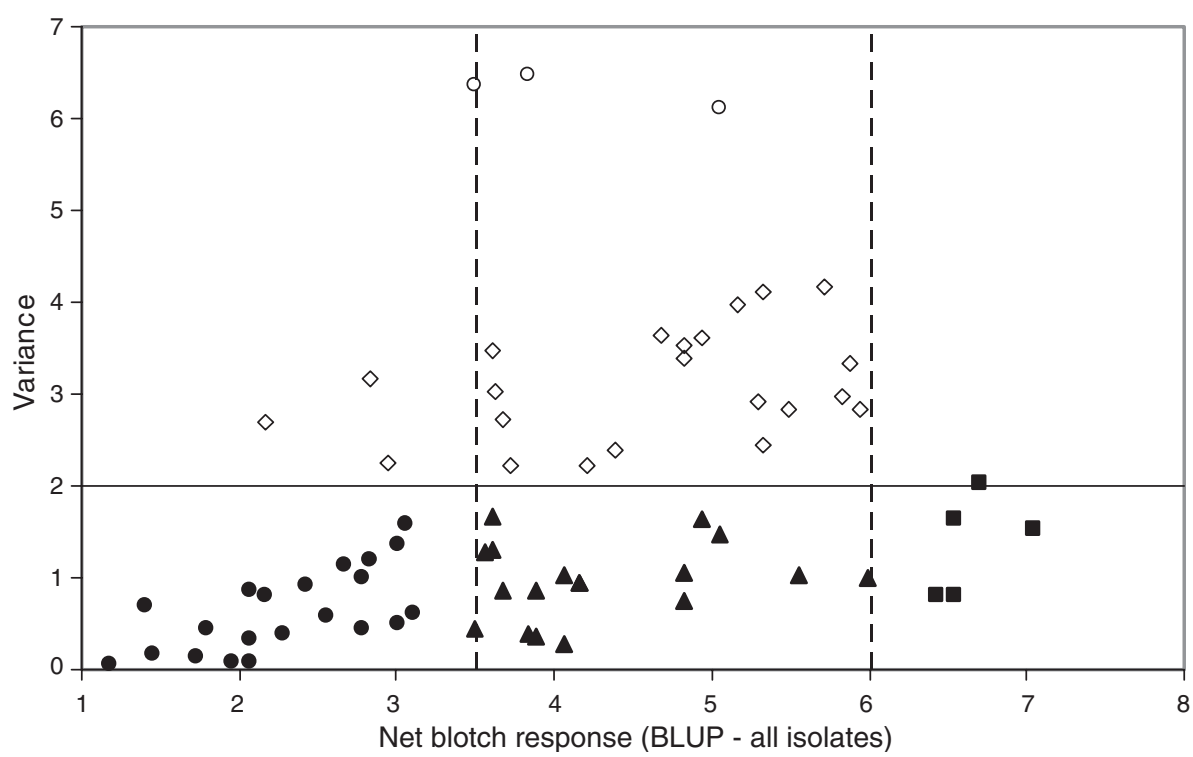

Fig. 1. Seedling responses of 69 barley lines to 9 isolates of Pyrenophora teres f. teres categorised by overall best linear unbiased predictor (BLUP) of infection response and variance of infection response among isolates: $\bullet$, low infection response with low variance; $\boldsymbol{\Lambda}$, intermediate response with low variance; $\mathbf{\square}$, high response with low variance; $\diamond$, intermediate infection response with high variance; $\bigcirc$, very high variance.

for line was large $\left(\sigma_{\mathrm{L}}^{2}=1.95\right)$ as was the effect of isolate $\times$ line interaction $\left(\sigma_{\mathrm{IL}}{ }^{2}=1.78\right)$. The variance among pathogen isolates was much smaller $\left(\sigma_{\mathrm{I}}^{2}=0.03\right)$.

The responses of phase 1 lines to net blotch were categorised into low $(<3.5)$, intermediate $(3.5-5.9)$, and high (6 or over) infection response classes on the basis of their overall BLUPs of infection response and variance of infection response across the 9 isolates (Fig. 1). Twenty-four lines with BLUP values for the infection response less than 3.5 were classified as resistant. Twenty-one of these lines were resistant to all isolates and had variances $<2$. The remaining 3 lines were resistant to most isolates and had variances greater than 2 (Table 1).

A further 18 lines gave BLUP infection responses in the range 3.5-5.9 with variances $<2$. These lines were Alexis, Algerian, Canadian Lake Shore, Cape, Clipper, Dairokkaku, Harbin, Kaputar, Koala, Mimosa, Morex, Onslow, Schooner, WA1184, WA4688, WA6389, WA6500, and WB134-22. These lines expressed intermediate response to all isolates. Five lines, Stirling, WB170-4, WB190-7, WI-2868, and WI-2976, were susceptible to all isolates, expressing BLUPs $\geq 6$ with low variance. Among these, Stirling and WB170-4 had lower variance than the other 3 lines. The remaining 22 lines gave intermediate BLUP infection responses with high to very high variances resulting from specific isolate $\times$ variety interaction.

\section{Adult plant responses}

Adult NTNB response on 66 lines was observed over 2 years in the field (Table 2). Significant variation was
Table 1. Ranking of the 24 barley lines with the best overall seedling resistance to 9 Australian isolates of Pyrenophora teres f. teres

\begin{tabular}{lcc}
\hline Line & Overall net blotch response ${ }^{\mathrm{A}}$ & Variance \\
\hline & Resistant to 9 isolates \\
WA 5149 & 1.2 & \\
WA 4794 & 1.4 & 0.1 \\
WA 4791 & 1.5 & 0.7 \\
CI9819 & 1.7 & 0.2 \\
CI5791 & 1.8 & 0.1 \\
CI7584 & 2.0 & 0.5 \\
WPG8412-9-2-1 & 2.1 & 0.1 \\
CI9214 & 2.1 & 0.1 \\
WA5769 & 2.1 & 0.3 \\
Heartland & 2.2 & 0.8 \\
Rojo & 2.3 & 0.8 \\
WA5182 & 2.4 & 0.4 \\
CI9776 & 2.6 & 0.9 \\
Psaknon & 2.7 & 0.6 \\
Tifang & 2.8 & 1.1 \\
W94\%175 & 2.8 & 0.4 \\
Steptoe & 2.8 & 1.0 \\
Den-4D & 3.0 & 1.2 \\
Coast & 3.0 & 0.5 \\
CM72 & 3.1 & 1.4 \\
Bonanza & 3.1 & 1.6 \\
& Resistant to most isolates & 0.6 \\
WA4833 & 2.2 & \\
Pompadour & 2.8 & 2.7 \\
Prato & 2.9 & 3.2 \\
& & 2.3 \\
A Bestinga & &
\end{tabular}

${ }^{\mathrm{A}}$ Best linear unbiased predicted (BLUP) values. 
Table 2. Infection responses (scale 0-9) and per cent disease severity to Pyrenophora teres f. teres in 66 barley lines evaluated in the field over 2 years

Values for per cent disease are angular transformations, with re-transformed values in parentheses

\begin{tabular}{|c|c|c|c|c|c|c|c|c|c|}
\hline \multirow[t]{2}{*}{ Line } & \multicolumn{2}{|c|}{1997} & \multicolumn{2}{|c|}{1998} & \multirow[t]{2}{*}{ Line } & \multicolumn{2}{|c|}{1997} & \multicolumn{2}{|c|}{1998} \\
\hline & IR & $\%$ Disease & IR & $\%$ Disease & & IR & $\%$ Disease & IR & $\%$ Disease \\
\hline Abyssinian & 2.5 & $13(5)$ & 4.0 & $19(10)$ & Psaknon & - & - & 3.0 & $6(1)$ \\
\hline Alexis & 5.0 & $23(15)$ & 5.5 & $12(4)$ & Reinette & 2.0 & $14(6)$ & 3.3 & $9(3)$ \\
\hline Algerian & 3.0 & $12(4)$ & 3.8 & $14(6)$ & Rika & 2.0 & $14(6)$ & 4.5 & $15(6)$ \\
\hline Beecher & 2.8 & $14(6)$ & 3.5 & $12(4)$ & Rojo & 3.0 & $13(5)$ & 1.8 & $0(0)$ \\
\hline Bonanza & 2.0 & $13(5)$ & 3.5 & $0(0)$ & Schooner & 5.0 & $15(7)$ & 5.0 & $15(7)$ \\
\hline Canadian Lake Shore & 3.5 & $14(6)$ & 4.3 & $6(1)$ & Skiff & 3.0 & $21(13)$ & 3.8 & $14(6)$ \\
\hline CI4922 & 2.5 & $10(3)$ & 4.8 & $14(6)$ & Steptoe & 3.0 & $20(11)$ & 2.5 & $6(1)$ \\
\hline CI5791 & 3.0 & $11(4)$ & 3.3 & $3(0)$ & Stirling & 7.0 & $19(11)$ & 6.5 & $26(19)$ \\
\hline CI7584 & 2.0 & $10(3)$ & 1.8 & $3(0)$ & Sutter & - & - & 6.3 & $37(36)$ \\
\hline CI9214 & 2.0 & $7(1)$ & 2.8 & $0(0)$ & Tifang & 2.0 & $10(3)$ & 3.5 & $0(0)$ \\
\hline CI9776 & 2.5 & $10(3)$ & 3.3 & $7(2)$ & UC566 & - & - & 6.3 & $18(9)$ \\
\hline CI9819 & 1.5 & $10(3)$ & 2.5 & $0(0)$ & W94\%175 & - & - & 2.8 & $6(1)$ \\
\hline CI1 1458 & 1.5 & $7(1)$ & 3.5 & $13(5)$ & WA1184 & - & - & 3.7 & $9(3)$ \\
\hline Clipper & 4.0 & $13(5)$ & 5.8 & $14(6)$ & WA4664 & 4.5 & $10(3)$ & 4.8 & $8(2)$ \\
\hline CM72 & 3.0 & $13(5)$ & 2.8 & $9(3)$ & WA4666 & 2.0 & $11(3)$ & 3.5 & $12(4)$ \\
\hline Coast & 2.0 & $10(3)$ & 1.8 & $6(1)$ & WA4688 & 3.0 & $21(13)$ & 4.3 & $16(7)$ \\
\hline Dampier & 7.0 & $24(16)$ & 7.0 & $18(10)$ & WA4791 & 1.0 & $11(4)$ & 2.0 & $0(0)$ \\
\hline Den-4D & - & - & 2.3 & $0(0)$ & WA4794 & 1.0 & $12(5)$ & 3.8 & $2\left(\begin{array}{ll}0 & 0\end{array}\right.$ \\
\hline Franklin & 3.3 & $17(8)$ & 5.0 & $14(6)$ & WA4833 & 2.0 & $15(7)$ & 5.0 & $11(4)$ \\
\hline Galaxy & 3.5 & $13(5)$ & 4.5 & $13(5)$ & WA4901 & 2.0 & $15(7)$ & 1.8 & $4(1)$ \\
\hline Grimmett & 4.5 & $15(7)$ & 6.3 & $15(7)$ & WA4913 & 4.0 & $16(7)$ & 4.0 & $10(3)$ \\
\hline Heartland & 2.0 & $15(6)$ & 3.5 & $0(0($ & WA5149 & - & - & 2.8 & $4(1)$ \\
\hline Hudson & - & - & 3.8 & $10(3)$ & WA5182 & 2.0 & $15(6)$ & 2.8 & $9(2)$ \\
\hline Igri & 3.5 & $22(13)$ & 6.0 & $16(8)$ & WA5769 & 1.5 & $11(3)$ & 2.5 & $1(0)$ \\
\hline Kaputar & 2.5 & $11(4)$ & 4.3 & $16(8)$ & WA6372 & - & - & 2.5 & $0(0)$ \\
\hline Koala & 2.5 & $17(9)$ & 3.8 & $9(3)$ & WA6389 & - & - & 4.3 & $9(2)$ \\
\hline Moondyne & 4.0 & $14(6)$ & 5.3 & $14(6)$ & WA6500 & - & - & 3.4 & $10(3)$ \\
\hline Morex & 6.0 & $16(8)$ & 5.3 & $19(10)$ & WB134-22 & 3.0 & $16(7)$ & 3.5 & $4(1)$ \\
\hline OK82850 & 2.5 & $10(3)$ & 3.8 & $8(2)$ & WB170-4 & 7.0 & $33(29)$ & 6.0 & $25(17)$ \\
\hline Onslow & 6.0 & $14(6)$ & 4.3 & $20(12)$ & WB190-7 & 6.0 & $31(26)$ & 7.0 & $27(20)$ \\
\hline Perun & 2.5 & 17 (9) & 3.3 & $5(1)$ & WI-2868 & 6.0 & $16(7)$ & 6.3 & $20(12)$ \\
\hline Pompadour & 1.0 & $7(2)$ & 3.0 & $8(2)$ & WI-2976 & 4.5 & $16(7)$ & 5.8 & $40(41)$ \\
\hline Prato & 2.5 & $18(9)$ & 2.8 & $6(1)$ & WPG8412-9-2-1 & 1.0 & $6(1)$ & 2.5 & $4(1)$ \\
\hline$P$ & $<0.001$ & $<0.001$ & $<0.001$ & $<0.001$ & & & & & \\
\hline 1.s.d. $(P=0.05)$ & 1.4 & 6 & 1.1 & 11 & & & & & \\
\hline $\mathrm{CV} \%$ & 20 & 19 & 11 & 49 & & & & & \\
\hline
\end{tabular}

observed among the lines for adult plant infection response and percent diseased leaf area. Thirty-seven lines in 1997 and 24 lines in 1998 had infection responses $<3.5$ (resistant). Eighteen lines had infection responses $<3.5$ in both years. Five lines in 1997 and 9 lines in 1998 had infection responses $\geq 6$ (susceptible). Four lines with infection responses $\geq 6$ were common in 1997 and 1998.

The remaining lines had intermediate responses. Adult plant infection responses of most of the lines showed little variation between the 2 years except for lines CI4922, CI11458, Igri, and WA4833 (Table 2). These 4 lines showed a higher response in 1998.

\section{Seedling v. adult plant responses}

An isolate (97NB1) of the pathogen collected from the 1997 field screening was used to test the same lines at the seedling stage. A comparison of the seedling infection responses against the adult plant responses observed in the field in 1997 showed that they were highly correlated $\left(R^{2}=0.64\right)$ (Fig. 2). No lines were observed that showed adult plant susceptibility combined with seedling resistance.

Characterisation of phase 2 lines: parents from Australian Barley Molecular Marker Program mapping populations

Forty-two lines used as parents to generate the various Australian mapping populations that were screened against 9 


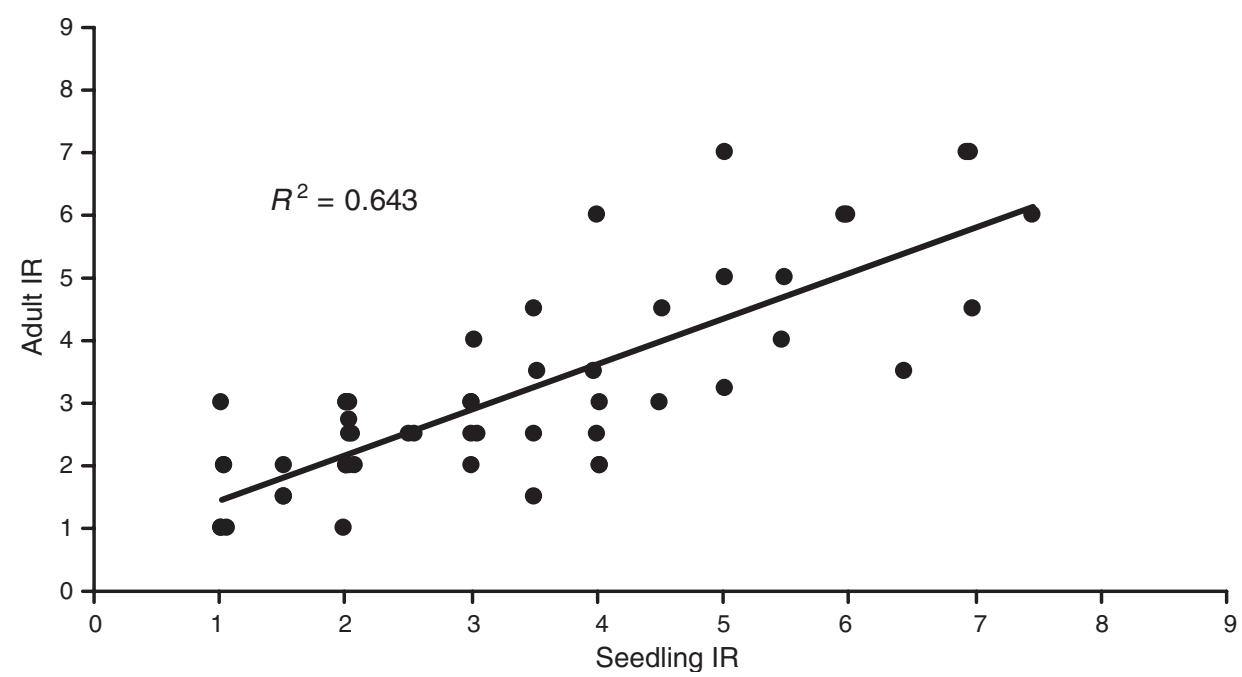

Fig. 2. Relationship between infection responses (0-9) of barley lines to Pyrenophora teres f. teres when evaluated in controlled environment seedling tests with isolate $97 \mathrm{NB} 1$ and in field tests on adult plants.

isolates of NTNB in 2000 and 2001 at the seedling stage are shown in Table 3. Isolate was fitted as a fixed effect because there were only 4 isolates common to both 2000 and 2001 experiments. The isolate effect was significant $(P<0.001)$. The model fitted random effects due to trial, set within trial, line, line $\times$ isolate interaction, line $\times$ trial interaction, and entry $\times$ isolate $\times$ trial interaction. Significant line $\times$ isolate effects were observed among the 9 isolates. The variance component for line was large $\left(\sigma_{\mathrm{L}}{ }^{2}=3.00\right)$ as was the effect of isolate $\times$ line interaction $\left(\sigma_{\mathrm{IL}}^{2}=3.05\right)$. Variance components for trial $\times$ line $\left(\sigma_{\mathrm{TL}}{ }^{2}=0.17\right)$ and trial $\times$ line $\times$ isolate $\left(\sigma_{\mathrm{TLI}}^{2}=0.41\right)$ were relatively small.

Barley lines CPI71284-48, AC Metcalfe, ND11231, VB9104, WA4794, and WPG8412-9 were resistant to moderately resistant to all the isolates (Table 3). Resistance to most isolates was expressed in CI9214 (intermediate response to NB34) and Pompadour (susceptible to NB54), whereas Forrest was moderately resistant to most isolates but susceptible to NB34.

Some lines were susceptible to most isolates. Gilbert was susceptible to 8 isolates but moderately resistant to NB29; Harrington and Klaxon were susceptible to 7 of 8 isolates tested and were moderately resistant to NB81. Barque was susceptible to all 5 isolates against which it was tested.

Most of the remaining barley lines showed differential responses to the range of $P$. teres $\mathrm{f}$. teres isolates. The parents of 10 principal mapping populations showed contrasting responses to 8 of the 9 isolates (Tables 3 and 4). VB9524 $\times$ ND11231 showed contrasting responses to 6 isolates; Tallon $\times$ Kaputar to 4; Chebec $\times$ Harrington and Tallon $\times$ Scarlett to 3 each; Arapiles $\times$ Franklin and WABAR2080 $\times$ AC Metcalfe to 2 each; and Alexis $\times$ Sloop, CPI71284-48 $\times$ Barque, Halcyon $\times$ Sloop, and VB9104 $\times$ Dash against
1 isolate each. Isolate NB81 did not differentiate between the parents of any of these populations. The parents of several populations showed differential responses to the same isolate (e.g. 6 parent pairs to NB97), whereas Alexis $\times$ Sloop and Halcyon $\times$ Sloop could only be separated by 1 isolate, NB34 and NB50, respectively.

\section{Discussion}

Finding sources of NTNB resistance effective against diverse pathotypes and subsequent mapping in segregating barley populations is important for their utilisation in breeding programs. Many lines in phase 1 had good resistance to a diverse range of Australian isolates. Many genotypes had spring habit that would facilitate incorporation of resistances into adapted Australian spring varieties. Wild barleys were not included in the study because of the difficulty in developing commercial malting varieties derived from them.

A total of 9 isolates identified in a survey of the Australian net blotch population (Platz et al. 2000) represented 7 distinct pathotypes and covered most of the Australian virulences including those present in New South Wales and Victoria. Therefore the barley lines resistant to these isolates are particularly relevant for Australian breeding programs and are a priority for development of molecular markers to enable marker assisted selection.

Twenty-one resistant lines were uniform in their responses to the range of isolates tested and thus provide valuable sources of resistance for all Australian barley regions. Eight (CI9819, CI5791, CI9214, Heartland, CI9776, Tifang, Steptoe, CM72) of these 24 barley lines have been studied by other workers. CI5791 and CI9819 were 
Table 3. Seedling net blotch infection responses of 42 barley lines, including parents of populations in the Australian Barley Molecular Marker Program, screened against 9 Australian isolates of Pyrenophora teres f. teres in 2000 and 2001

\begin{tabular}{|c|c|c|c|c|c|c|c|c|c|}
\hline \multirow[t]{2}{*}{ Barley lines } & \multicolumn{9}{|c|}{ Net blotch response $\mathrm{e}^{\mathrm{A}}$} \\
\hline & NB29 & NB32 & NB34 & NB50 & NB52B & NB54 & NB77 & NB81 & NB97 \\
\hline Alexis & - & 5 & 4 & 8 & 8 & 9 & 7 & 3 & 7 \\
\hline Arapiles & 7 & 5 & 10 & 9 & 9 & 9 & 9 & 4 & 9 \\
\hline B87/14 & - & 2 & 6 & 4 & 5 & 5 & 3 & 1 & 3 \\
\hline Barque & 6 & 6 & - & 8 & - & 7 & 8 & - & - \\
\hline Beecher & 9 & 2 & - & 2 & - & 2 & 2 & - & - \\
\hline Blenheim & - & 2 & 5 & 7 & 6 & 6 & 5 & 2 & 3 \\
\hline Brindabella & - & 4 & 4 & 8 & 7 & 7 & 5 & 2 & 6 \\
\hline Chariot & - & 2 & 6 & 6 & 4 & 9 & 7 & 1 & 3 \\
\hline Chebec & - & 5 & 7 & 7 & 8 & 6 & 6 & 3 & 6 \\
\hline CI11458 & 1 & 1 & 5 & 4 & 5 & 8 & 4 & 1 & 2 \\
\hline CI9214 & - & 3 & 5 & 1 & 2 & 1 & 1 & 1 & 1 \\
\hline Corvette & 4 & 9 & 9 & 4 & 2 & 4 & 4 & 8 & 4 \\
\hline CP171284-48 & 3 & 2 & - & 4 & - & 4 & 3 & - & - \\
\hline Dash & 3 & 3 & - & 5 & - & 4 & 3 & - & - \\
\hline Forrest & - & 4 & 9 & 4 & 3 & 3 & 4 & 3 & 3 \\
\hline Franklin & - & 3 & 3 & 9 & 9 & 9 & 5 & 2 & 2 \\
\hline Gairdner & - & 4 & 4 & 4 & 5 & 5 & 4 & 3 & 5 \\
\hline Galleon & - & 5 & 7 & 4 & 9 & 4 & 4 & 3 & 5 \\
\hline Gilbert & 4 & 8 & 9 & 9 & 10 & 10 & 9 & 7 & 9 \\
\hline Halcyon & 4 & 4 & - & 5 & - & 7 & 6 & - & - \\
\hline Harrington & - & 7 & 8 & 8 & 9 & 9 & 8 & 4 & 7 \\
\hline Kaputar & 6 & 4 & 5 & 6 & 5 & 4 & 5 & 2 & 5 \\
\hline Klaxon & - & 7 & 9 & 9 & 9 & 9 & 9 & 5 & 9 \\
\hline AC Metcalfe & 1 & 1 & - & 3 & - & 2 & 2 & - & - \\
\hline ND11231*12 & - & 2 & 2 & 4 & 1 & 3 & 1 & 1 & 2 \\
\hline Patty & - & 1 & 3 & 9 & 9 & 8 & 4 & 1 & 2 \\
\hline Pompadour & - & 1 & 4 & 3 & 3 & 7 & 2 & 1 & 2 \\
\hline Prior & - & 8 & 9 & 2 & 3 & 5 & 2 & 9 & 3 \\
\hline Q21861 & - & 3 & 3 & 4 & 5 & 5 & 5 & 3 & 4 \\
\hline Scarlett & - & 2 & 3 & 5 & 9 & 7 & 3 & 1 & 1 \\
\hline Skiff & 2 & 2 & 7 & 8 & 9 & 7 & 5 & 1 & 2 \\
\hline Sloop & 3 & 5 & 7 & 9 & 8 & 8 & 7 & 4 & 7 \\
\hline Stirling & - & 5 & 6 & 7 & 5 & 5 & 4 & 4 & 3 \\
\hline Tallon & 3 & 3 & 3 & 8 & 6 & 10 & 8 & 4 & 8 \\
\hline Tantangara & - & 2 & 8 & 7 & 8 & 5 & 4 & 2 & 3 \\
\hline Tilga & - & 7 & 7 & 6 & 7 & 5 & 5 & 4 & 3 \\
\hline VB9104 & 2 & 2 & 3 & 3 & 4 & 4 & 3 & 1 & 3 \\
\hline VB9524 & - & 4 & 7 & 8 & 9 & 8 & 8 & 4 & 8 \\
\hline WA4794 & - & 1 & 1 & 1 & 2 & 1 & 1 & 1 & - \\
\hline WABAR2080 & 2 & 5 & 7 & 8 & 7 & 6 & 4 & 4 & 5 \\
\hline WB220 & 5 & 4 & - & 8 & - & 6 & 8 & - & - \\
\hline WPG8412-9 & - & 1 & 1 & 3 & 1 & 3 & 1 & 1 & 1 \\
\hline \multirow[t]{2}{*}{ 1.s.d. $(P=0.05)$} & & & Av. & & 1.5 & & & & \\
\hline & & & Max. & & 2.6 & & & & \\
\hline
\end{tabular}

${ }^{\mathrm{A}}$ Best linear unbiased predicted (BLUP) values.

identified as resistant by Buchannon and McDonald (1965) and Khan (1971). Since Gupta and Loughman (2001) found that the NTNB virulences have not changed over a 20 -year period in Western Australia, the resistance in these lines remains effective. Afanasenko et al. (1995) also found CI5791, CI9819, and Tifang to be the most resistant lines against Russian, German, Czech, and Slovak P. teres f. teres isolates, indicating that the resistances effective against Australian isolates were also effective against Russian and European isolates. Legge et al. (1996) included CI5791 as a resistant control in studies using Canadian isolates. They also included the lines CI9214 (intermediate in response), Heartland (susceptible), and Steptoe and CM72 (both resistant). The intermediate response of CI9214 and 
Table 4. Parents of principal mapping populations from the Australian Barley Molecular Marker Program showing contrasting responses to Pyrenophora teres f. teres, summarised from Table 3

Numbers separated by a slash represent the responses of parent 1 and parent 2, respectively, for each isolate

\begin{tabular}{|c|c|c|c|c|c|c|c|c|c|c|}
\hline \multicolumn{2}{|c|}{ Mapping populations } & \multirow[b]{2}{*}{ NB29 } & \multirow[b]{2}{*}{ NB32 } & \multicolumn{5}{|c|}{ Summary of net blotch response Parent $1 /$ Parent 2} & \multirow[b]{2}{*}{ NB81 } & \multirow[b]{2}{*}{ NB97 } \\
\hline Parent1 & Parent2 & & & NB34 & NB50 & NB52B & NB54 & NB77 & & \\
\hline Alexis & Sloop & & & $7 / 4$ & & & & & & \\
\hline Arapiles & Franklin & & & $10 / 3$ & & & & & & $9 / 2$ \\
\hline CPI71284-48 & Barque & & & & $4 / 8$ & & & & & \\
\hline WABAR2080 & Metcalfe & & & & $8 / 3$ & & $6 / 2$ & & & \\
\hline Chebec & Harrington & & $2 / 6$ & & & $4 / 8$ & & & & $3 / 7$ \\
\hline Halcyon & Sloop & & & & $5 / 9$ & & & & & \\
\hline Tallon & Scarlett & & & & $8 / 5$ & & & $8 / 3$ & & $8 / 1$ \\
\hline Tallon & Kaputar & $3 / 6$ & & & & & $10 / 4$ & $8 / 5$ & & $8 / 5$ \\
\hline VB9104 & Dash & & & & $3 / 5$ & & & & & \\
\hline VB9524 & ND11231 & & & $7 / 2$ & $8 / 4$ & $9 / 1$ & $8 / 3$ & $8 / 1$ & & $8 / 2$ \\
\hline
\end{tabular}

susceptibility of Heartland and Bonanza suggest that the NTNB virulences in Canada are different from Australia. The resistance of CI5791, Steptoe, and CM72 to both Australian and Canadian isolates indicates that this resistance is effective against a wide range of virulences. CI9776 and Tifang were also tested with 6 Swedish isolates (Jonsson et al. 1997). CI9776 was resistant and Tifang was intermediate in reaction against these isolates, further demonstrating the broad spectrum of resistance present in some barley genotypes. The high correlation between responses of seedling and adult plants indicated that seedling screening would be useful to select for field resistance.

Parent screening in phase 2 showed contrasting responses to a range of $P$. teres f. teres isolates (Table 4), indicating that resistance genes in these populations should segregate. Screening in phase 2 identified existing mapping populations that may be used to map NTNB resistances and identify markers linked to the resistances (Cakir et al. 2003, this issue; Raman et al. 2003, this issue). This work has enabled identification of resistance loci from different sources (Kaputar, Halcyon, ND11231). Further mapping work is in progress with resistant parents CI9214, Pompadour, WA4794, WPG8412-9 and another 6 segregating populations.

Lines identified in this work are useful sources of resistance to NTNB and can be utilised directly in barley breeding programs. The mapping of gene(s) segregating in these populations to different loci provides the opportunity to use gene combinations and pyramid them using molecular markers in resistance breeding programs.

\section{Acknowledgments}

We thank Jane Speijers of WA Department of Agriculture for statistical analysis. We also thank Grains Research and Development Corporation, Grain Pool of Western Australia, Joe White, and Kirin Maltings for financial support.

\section{References}

Afanasenko OS, Hartleb H, Guseva NN, Minarikova V, Janosheva M (1995) A set of differentials to characterize populations of Pyrenophora teres Drechs. for international use. Journal of Phytopathology 143, 501-507.

Arabi MI, Barrault G, Sarrafi A, Albertini L (1992) Variation in the resistance of barley cultivars and in the pathogenicity of Drechslera teres f. maculata and D. teres f. teres isolates from France. Plant Pathology 41, 180-186.

Buchannon KW, McDonald WC (1965) Sources of resistance in barley to Pyrenophora teres. Canadian Journal of Plant Science 45, 189193.

Cakir M, Gupta S, Platz GJ, Ablett GA, Loughman R, Emebiri LC, Poulsen D, Li CD, Lance RCM, Galway NW, Jones MGK, Appels R (2003) Mapping and validation of the genes for resistance to Pyrenophora teres f. teres in barley (Hordeum vulgare L.). Australian Journal of Agricultural Research 54, 1369-1377.

Deadman ML, Cooke BM (1987) Effects of net blotch on growth and yield of spring barley. Annals of Applied Biology 110, 33-42.

Douiyssi A, Rasmusson DC, Roelfs AP (1998) Responses of barley cultivars and lines to isolates of Pyrenophora teres. Plant Disease 82, 316-321.

Graner A, Foroughi-Wehr B, Tekauz A (1996) RFLP mapping of a gene in barley conferring resistance to net blotch (Pyrenophora teres). Euphytica 91, 229-234.

Gupta S, Loughman R (2001) Current virulence of Pyrenophora teres on barley in Western Australia. Plant Disease 85, 960-966.

Hampton JG, Arnst BJ (1978) The relationship between net blotch and yield loss in spring barley. In 'Epidemiology and crop loss assessment. Proceedings APPS Workshop'. Lincoln College, New Zealand. pp. 18-1-18-4 (Australasian Plant Pathology Society in cooperation with Lincoln College)

Jana S, Bailey KL (1995) Responses of wild and cultivated barley from West Asia to net blotch and spot blotch. Crop Science 35, 242-246.

Jonsson R, Bryngelsson T, Gustafsson M (1997) Virulence studies of Swedish net blotch isolates (Drechslera teres) and identification of resistant barley lines. Euphytica 94, 209-218. doi:10.1023/ A:1002924424200.

Khan TN (1971) Turkish barley varieties as a source of resistance to net blotch. Euphytica 20, 292-298.

Khan TN (1982) Changes in pathogenicity of Drechslera teres relating to changes in barley cultivars grown in Western Australia. Plant Disease 66, 655-656. 
Khan TN (1987) Relationship between net blotch (Drechslera teres) and losses in grain yield of barley in Western Australia. Australian Journal of Agricultural Research 38, 671-679.

Legge WG, Metcalfe DR, Chiko AW, Martens JW, Tekauz A (1996) Reaction of Turkish barley accessions to Canadian barley pathogens. Canadian Journal of Plant Science 76, 927-931.

Manninen O, Kalender R, Robinson J, Schulman AH (2000) Application of BARE-1 retrotransposon markers to the mapping of a major resistance gene for net blotch in barley. Molecular and General Genetics 264, 325-334. doi:10.1007/S004380000326.

Mathre DE (1997) 'Compendium of barley diseases.' (American Phytopathological Society Publishing: St Paul, MN)

Platz GJ, Bell KL, Rees RG, Galea VJ (2000) Pathotype variation of the Australian net blotch population. In 'Proceedings of the 8th International Barley Genetics Symposium'. (Ed. S Logue) pp. 160162. (Manning Press: Adelaide, SA)

Poulsen DME, Johnston RP, Platz GJ, Fox G, Kelly A, Sturgess JM, Fromm RL, Laufer MJ, Inkerman PA, Butler D (1999) Effects of foliar diseases on Northern Region grain production in the 1998 winter cropping season. In 'Proceedings of the 9th Australian Barley Technical Symposium. Melbourne, Australia'. (Eds DB Moody, RG Flood) pp. 2.20.01-2.20.05. (Publishers: The Organising Committee, 9th Australian Barley Technical Symposium)

Raman H, Platz GJ, Chalmers KJ, Raman R, Read BJ, Barr AR, Moody DB (2003) Mapping of genomic regions associated with net form of net blotch resistance in barley. Australian Journal of Agricultural Research 54, 1359-1367.

Sato K, Takeda K (1997) Net blotch resistance in wild species of Hordeum. Euphytica 95, 179-185. doi:10.1023/A:1002958924439.
Speakman JB, Pommer EH (1986) A simple method for producing large volumes of Pyrenophora teres spore suspension. Bulletin of British Mycological Society 20, 129-130.

Steffenson BJ, Hayes PM, Kleinhofs A (1996) Genetics of seedling and adult plant resistance to net blotch (Pyrenophora teres f. teres) and spot blotch (Cochliobolus sativus) in barley. Theoretical and Applied Genetics 92, 552-558. doi:10.1007/S001220050162.

Steffenson BJ, Webster RK (1992) Pathotype diversity of Pyrenophora teres f. teres on barley. Phytopathology 82, 170-177.

Steffenson BJ, Webster RK, Jackson LF (1991) Reduction in yield loss using incomplete resistance to Pyrenophora teres f. teres in barley. Plant Disease 75, 96-100.

Sutton JC, Steele P (1983) Effects of seed and foliar fungicides on progress of net blotch and yield of barley. Canadian Journal of Plant Science 63, 631-639.

Tekauz A (1985) A numerical scale to classify reactions of barley to Pyrenophora teres. Canadian Journal of Plant Pathology 7, 181183.

Tekauz A (1990) Characterization and distribution of pathogenic variation in Pyrenophora teres $\mathrm{f}$. teres and P. teres $\mathrm{f}$. maculata from western Canada. Canadian Journal of Plant Pathology 12, 141148 .

Zadoks JC, Chang TT, Konzak CF (1974) A decimal code for the growth stages of cereals. Weed Research 14, 415-421.

Manuscript received 25 January 2003, accepted 1 August 2003 